\title{
Has there been any structural convergence in the transmission of European monetary policies?
}

\author{
by \\ Andrew Hughes Hallett \\ and \\ Christian Richter ${ }^{\ddagger}$
}

\begin{abstract}
:
This paper makes three contributions. First we present a technique by which the monetary transmission mechanism of Germany, France, the UK and the Eurozone can be decomposed into its component cycles, compared across economies and across time. As a result, we found that the individual data generating processes have varied over time. Second we show that Germany has now converged on the rest of Europe and not vice versa, although Germany had dominated monetary policy making in Europe for many years. Third, we show that the UK as an outsider has behaved like a peripheral EMU country, even when EMU was not in place. In other words, the transmission mechanisms of Germany and the UK were fundamentally different. Hence, when that German monetary policy dominated Europe in a way that was not in line with the rest of Europe, never mind the UK, it is no surprise that the UK eventually left the ERM (1992). The current financial crisis may enforce the trend of convergence of the transmission mechanism. But there have been signs of a divergence between core and periphery, to some extent involving the UK, so this general convergence, as opposed to tighter convergence in the core, may not last.
\end{abstract}

Keywords: Time-Frequency Analysis, Transmission Mechanism, Convergence, Monetary Policy

JEL Classification: C22, C29

November 2008

$¥$ Andrew Hughes Hallett: George Mason University and CEPR; School of Public Policy, 4400 University Drive, Fairfax, VA 22030, USA, Tel: +1-703-933-2280; and Department of Economics, University of St Andrews, Scotland. Email: ahughesh@gmu.edu, Christian Richter: School of Economics, Kingston University, Penrhyn Road, Kingston upon Thames, KT1 2EE, UK, Tel: +44-(0)20-8547-7343, Email: C.Richter@Kingston.ac.uk. 


\section{Introduction}

In this paper we analyse the transmission mechanisms for monetary policy in the European Union and Eurozone, from short term interest rates to their impact on annual growth rates. Specifically, we examine the transmission mechanisms for a common monetary policy in Germany, France, and the Eurozone as a whole, for signs of structural convergence over the past thirty years; and compare those to the transmission mechanism of an outsider, the UK, who did not join the single currency but who was subject to many of the same economic events and pressures on monetary policy. Several authors ${ }^{1}$ have pointed out that a successful currency union (and a common monetary policy) requires symmetric structures, as well as shocks, across the union so that even common shocks provoke similar responses and have similar effects in the different member states. Monetary transmissions are therefore the prime example of where structural convergence is needed since monetary policy changes are the crucial case of a common shock that we need to have a common impact across the union. Without that the single monetary policy cannot be expected to work smoothly or represent an improvement over separate policies/currencies. Testing for convergence in monetary transmissions is therefore a genuine test of integration, provided it is not part of a general tendency seen also among outsiders and in the rest of the world.

In general, the monetary transmission mechanism describes how policy-induced changes in the nominal money stock or the short-term nominal interest rate impact on real variables such as aggregate output and employment. Specific channels of monetary transmission operate through the effects that monetary policy has on interest rates, exchange rates, equity and real estate prices, bank lending, and firm balance sheets: see (Ireland and Boston, 2005). Recent research on the transmission mechanism seeks to understand how these channels work in the context of dynamic, stochastic, general equilibrium models (e.g Barran et al., 1995; Boivin and Giannoni, 2006; Fukuda, 1993; Golinelli and Rovelli, 2005; Goodhart and Hofmann, 2005; Kim and Korea, 2003; Lutkepohl and Wolters, 2003).

\footnotetext{
${ }^{1}$ BIS (1995), Dale and Haldane (1995), Ramaswamy and Sloek (1998), Hughes Hallett and Piscitelli (1999; 2002). Asymmetries in monetary transmissions can arise from variations in house ownership and household debt or mortgages (MacLennan et al., 2000); from variations in the financing of firms and hence the industrial structures in different economies (Kashyup and Stein, 1997; Carlino and DeFina, 1999); or from variations in the size of firms (industrial concentration), financial structures and the legal system (Cecchetti, 1999) - in short, from both the borrowing and the lending side of monetary transactions. Indeed, MacLennan et al (2000) argue that such "indirect" impacts of monetary asymmetries are likely to prove more difficult for policy to absorb that a lack of synchronisation in business cycles.
} 
However, in this paper we take a different tack. We focus on a statistical analysis of the link between the short term interest rates and the annual growth rate of an economy in a model free environment. In that way we avoid biasing our results, and avoid making them dependent on a specific model for which there may be less than consensus support. We particularly ask, what are the effects of monetary policy on the growth rate and are these effects similar across selected Eurozone (EMU) countries? Is monetary policy able to smooth the business cycle; or does it cause greater uncertainty?

For this purpose we investigate the transmission mechanism for Germany, France and the Eurozone, with the UK as the outside comparator. So far, empirical results suggest that the transmission mechanisms for those countries are different in each country (e. g. Dedola and Lippi, 2005; Kim and Korea, 2003; Lovrinovic et al., 2004; Peersman and Ghent, 2004; Schmidt, 2006). For the Eurozone countries these differences could be crucial for monetary policy effectiveness since the same interest rate can have different output effects in different places, making the use of a common monetary policy more difficult. Therefore it is important to test not only whether the transmission mechanisms are different, but in what sense they are different. The next question is whether these differences still persist under the Euro, or whether we can observe some sort of convergence within the Eurozone. However, in this paper we only focus on Germany and France, therefore our results are quite limited in terms of the Eurozone. But within the Eurozone, Germany and France represent a good $60 \%$ of total output, so it matters more whether the transmission mechanism of these countries are similar (or are becoming more similar) than it does for other countries.

In order to test for convergence of the transmission mechanism, we need to employ a time-varying approach. We cannot use a method which assumes a parameter structure which is constant over time, since that would exclude convergence in terms of changes in the underlying parameters of the transmission mechanisms. We therefore test for convergence using a time-frequency approach already well used in economics (Hughes Hallett and Richter (2002; 2004; 2006a; 2006b) and which is standard in the engineering literature (Boashash, 2003) But for the purpose of our analysis we only focus on the link between two variables. That is, we concentrate on the impact effects of monetary policy on the growth rate. As a proxy for monetary policy we use the market 3-month interest rate. However, and in contrast to Richter (2007), we test the impact of the interest change on the annual growth rate and not on the quarterly growth rate. The quarterly growth rate is the change from one quarter to another, whilst the annual growth rate measures the change from today to a year ago. Hence, the 
annual growth rate captures more long-term effects. As we will see, the results are significantly different to Richter (2007).

This paper is organised as follows: the following section gives a brief introduction into the time-frequency approach. Section three then presenting the empirical results, and section four draws the conclusions to be learned from the exercise.

\section{A Technical Introduction to Time Frequency Analysis}

Spectral analysis decomposes the variance of a sample of data across different frequencies. The power spectrum itself then shows the relative importance of the different cycles in creating movements in that data, and hence describes the cyclical properties of a particular time series. It is assumed that the fluctuations of the underlying data are produced by a large number of elementary cycles of different frequencies. Furthermore, it is usually assumed that the contribution of each cycle is constant throughout the sample. However, as Chauvet and Potter (2001) show for the US, business cycles cannot be assumed to be constant. Hence, the spectrum cannot be constant over time due to changing weights associated with each of the elementary cycles. A "traditional" frequency analysis cannot handle that case. But in recent years time frequency techniques have been developed which can do so. It depends on using a Wigner-Ville distribution for the weights (see for example: Matz and Hlawatsch, 2003).

In this paper we use a special case of the Wigner-Ville distribution, namely the "short time Fourier transform" (STFT). The STFT catches structural changes (here interpreted as changes of the underlying lag structure in accordance with Wells, 1996), but assumes local stationarity. We employ the STFT for two reasons: first, the time series we analyse are already in log-differenced form so stationarity may be assumed. Moreover, standard unit root tests performed on our data (specifically the ADF and Phillips-Perron tests, available on request) confirm that assumption. Finally, results available in the literature using similar data (Campbell and Mankiw, 1987; Clark, 1987; Todd, 2003; Watson, 1986) also confirm that conclusion. Secondly, if the time series is stationary, then the STFT and the Wigner-Ville distribution actually coincide (Boashash, 2003). Therefore, employing the Wigner-Ville distribution directly would not have changed our results.

All the data collected for our sample are real GDP, seasonally adjusted. Annualised growth rates are defined as: 


$$
\mathrm{y}_{\mathrm{t}}=\Delta^{4}\left(\log \left(\mathrm{Y}_{\mathrm{t}}\right)\right)=\log \left(\frac{\mathrm{Y}_{\mathrm{t}}}{\mathrm{Y}_{\mathrm{t}-4}}\right)
$$

In order to get time varying parameters into our framework, equation (2.2) below, we use the Kalman filter; and to do that we need to make initial parameter estimates to start the Kalman filter estimation. These initial parameter values are obtained by OLS estimation using the entire sample (see also Wells, 1996) ${ }^{2}$. Given these start values, we can then re-estimate the model parameters using the Kalman filter. We then employ a general to specific approach, eliminating insignificant lags using the sequential strategy specified below. The maximum number of lags was determined by the Akaike Criterion (AIC), and was found to be eight in one case and less in the others. Each time we ran a new regression we used a new set of initial parameter values. Then, for each regression we applied a set of diagnostic tests shown in the tables in Appendix 2, to confirm that the specification found was valid. The final parameter values are therefore filtered estimates, independent of their start values.

Suppose, we are interested in the relationship between two variables: $\left\{\mathrm{y}_{\mathrm{t}}\right\}$, say the UK growth rate, and $\left\{\mathrm{x}_{\mathrm{t}}\right\}$ the UK interest rate. We assume that they are related in the following way:

$$
\mathrm{V}(\mathrm{L})_{\mathrm{t}} \mathrm{y}_{\mathrm{t}}=\mathrm{A}(\mathrm{L})_{\mathrm{t}} \mathrm{x}_{\mathrm{t}}+\mathrm{u}_{\mathrm{t}}, \mathrm{u}_{\mathrm{t}} \sim \text { i.i.d. }\left(0, \sigma^{2}\right)
$$

where $\mathrm{A}(\mathrm{L})_{\mathrm{t}}$ and $\mathrm{V}(\mathrm{L})_{\mathrm{t}}$ are filters, and $\mathrm{L}$ is the lag operator such that $\mathrm{Ly}_{\mathrm{t}}=\mathrm{y}_{\mathrm{t}-1}$. Notice that the lag structure, $\mathrm{A}(\mathrm{L})_{\mathrm{t}}$, is time-varying. That means we need to use a state space model (such as the Kalman filter) to estimate the implied lag structure. That is

$$
\begin{aligned}
& \mathrm{v}_{\mathrm{i}, \mathrm{t}}=\mathrm{v}_{\mathrm{i}, \mathrm{t}-1}+\varepsilon_{\mathrm{i}, \mathrm{t}}, \text { for } \mathrm{i}=1, \ldots, \mathrm{p} \text { and } \varepsilon_{\mathrm{i}, \mathrm{t}} \sim\left(0, \sigma_{\varepsilon_{\mathrm{i}}}^{2}\right) \\
& \mathrm{a}_{\mathrm{i}, \mathrm{t}}=\mathrm{a}_{\mathrm{i}, \mathrm{t}-1}+\eta_{\mathrm{i}, \mathrm{t}}, \text { for } \mathrm{i}=0, \ldots, \mathrm{q} \text { and } \eta_{\mathrm{i}, \mathrm{t}} \sim\left(0, \sigma_{\eta_{\mathrm{i}}}^{2}\right)
\end{aligned}
$$

Tests for parameter variation: We test for the random walk property using the LaMotte-McWother (1978) test. For structural breaks, we employ the fluctuations test (Ploberger et al., 1989). Finally, we then use our general to specific approach to estimate

\footnotetext{
${ }^{2}$ Obviously, using the entire sample implies that we neglect possible structural breaks. The initial estimates may be biased therefore. The Kalman filter will then correct for this since, as Wells (1996) points out, the Kalman filter will converge to the true parameter value independently of the initial value. But choosing initial values which are already "close" to the true value accelerates convergence. Hence we employ an OLS estimate to start. And the start values have no effect on the parameter estimates by the time we get to 2008. Our results are robust.
} 
(2.2); starting off with lag lengths of nine and $\mathrm{p}=\mathrm{q}$, and dropping those lags which were never significant.

Sequential testing for significance: In general, using a time-varying model, (2.2)-(2.3), implies that we get parameter values for each point in time. Hence, a particular parameter could be significant for all points in time; or at some times but not others; or it might never be significant. The parameter changes are at the heart of this paper as they imply a change of the lag structure and a change in the spectral results. We therefore employed the following testing strategy: if a particular lag was never significant then this lag was dropped from the equation and the model was estimated again. If the AIC criterion was less than before, then that lag was completely excluded. If a parameter was significant for some periods but not others, it was kept in the equation with a parameter value of zero for those periods in which it was insignificant. This strategy minimised the AIC criterion, and leads to a parsimonious specification. Finally, before accepting the regression results found, we tested the residuals in each case for auto-correlation and heteroscedasticity.

Parameter and temporal stability tests: Specification (2.2)-(2.3) was then validated using two different stability tests. Both tests check for the same null hypothesis against differing temporal instabilities. The first is the fluctuations test of Ploberger et al. (1989), which detects discrete breaks at any point in time in the coefficients of a (possibly dynamic) regression. The second test is due to LaMotte and McWorther (1978), and is designed specifically to detect random parameter variation of a specific unit root form (our specification). We found that the random walk hypothesis for the parameters was justified for each country (results available on request). Finally, we chose the fluctuations test for detecting structural breaks because the Kalman filter allows structural breaks at any point and the fluctuations test is able to accommodate this. ${ }^{3}$ Thus, and in contrast to other tests, the fluctuations test is not restricted to any pre-specified number of breaks. ${ }^{4}$

Conversion to the frequency domain (spectral analysis): Once this regression is done, it gives us a time-varying ADL model. From this ADL model we can calculate the short-time

\footnotetext{
${ }^{3}$ Notice that all our tests of significance, and significant differences in parameters, are being conducted in the time domain, before transferring to the frequency domain, because no statistical tests exist for calculated spectra (the transformations being nonlinear and involving complex arithmetic). Stability tests are important here because our spectra are sensitive to changes in the underlying parameters (see section 3 ).

${ }^{4}$ The fluctuations test works as follows: one parameter value is taken as the reference value, e.g. the last value of the sample. All other observations are now tested whether they significantly differ from that value. In order to do so, Ploberger et al. (1989) have provided critical values that we have used. If the test value is above the critical value then we have a structural break, i.e. the parameter value differs significantly from the reference value.
} 
Fourier transform, as originally proposed by Gabor (1946), in order to determine the timevarying spectrum and co-spectrum. We briefly introduce the STFT in Appendix 1 to show how this is done: for details, the reader is referred to Boashash (2003). The basic idea is to find the spectrum of a signal $\mathrm{x}(\mathrm{t})$, at time $\mathrm{t}$, by analysing a small portion of the signal around that time period. These calculations can then be repeated for each time period in turn.

Structural convergence: Hence, by transferring the time domain results into the frequency domain, we can show how the relationship between two varaibles has changed in terms of individual frequencies. That allows us to investigate whether any convergence took place over time in terms of either outcomes or policy responses; and, if so, at which frequencies. As a measure of the similarity in policy responses, as opposed to increasing convergence in business cycles which would be represented by the coherence between two sets of output data, we use the gain. ${ }^{5}$ To see if there has been convergence in the monetary transmissions, we can compare these gains across countries.

Thus, having obtained estimates for the coefficients in (2.2), we need to calculate the gain from the cross-spectrum between $\left\{y_{t}\right\}$ and $\left\{x_{t}\right\}$. The gain is the frequency domain equivalent of a regression coefficient in the time domain. It changes an incoming signal to the outgoing signal. For the purpose of this paper therefore, it reflects the transmission mechanism: i.e. the strength with which the interest rate signal is transferred into the business cycle.

Calculating the gains: Hughes Hallett and Richter (2002; 2003a; 2003b; 2004) show that the time-varying cross spectrum $\left(\mathrm{f}_{\mathrm{YX}}(\omega)_{\mathrm{t}}\right)$ using the STFT is then equal to

$$
\mathrm{f}_{\mathrm{YX}}(\omega)_{\mathrm{t}}=\mathrm{T}(\omega)_{\mathrm{t}} \mathrm{f}_{\mathrm{XX}}(\omega)_{\mathrm{t}}
$$

where $T(\omega)_{t}$ is the transfer function obtained from the short time Fourier transforms of the weights $\left\{\mathrm{a}_{\mathrm{j}}\right\}_{\mathrm{j}=-\infty}^{\infty}$ and $\left\{\mathrm{v}_{\mathrm{i}}\right\}_{\mathrm{i}=-\infty}^{\infty}$. From here we can calculate the gains. As noted in Appendix 1, the traditional formulae can be used to do this at each point in time. The last term in (2.4), $f_{X X}(\omega)_{t}$, is the spectrum of the predetermined variable. This spectrum may be time varying as well. We can now calculate the gain (we are only interested in the gain in this paper) from

\footnotetext{
${ }^{5}$ This is not a complete picture of the transmission mechanism of course, but it does represent a necessary condition for convergence. Had we also been interested in similarities in the incidence or timing of the impacts of monetary policy changes, then we would have to compare phase shifts across countries too.
} 


$$
T(\omega)_{t}=\left(\sum_{b=1}^{q} a_{b, t} \exp (-j \omega b) /\left[1-\sum_{i=1}^{p} v_{i, t} \exp (-j \omega i)\right]\right), \text { for } b=1 \ldots q \text { and } i=1 \ldots p
$$

where $\mathrm{j}=\sqrt{ }-1$. The gain is then given by $A(\omega)_{t}=\left|T(\omega)_{t}\right|^{2}$.

Two comments: Our method allows us to overcome a major difficulty in this kind of analysis: namely that a very large number of observations would usually be necessary to carry out the necessary frequency analysis by direct estimation. This would be a particular problem in the case of structural breaks, since the sub-samples would typically be too small to allow the associated spectra to be estimated directly.

Second, in the following section we present the estimated time-varying gains dependent on the results of our fluctuations tests. One can see from these figures that the gains change. However, one cannot infer from those figures alone that the changes in the underlying spectra and co-spectra are statistically significant. The figures for the gains have to be accompanied by the fluctuation test results. Once a structural break has been identified by the fluctuations test, the results of that will show up as significant in the associated spectrum.

\section{Empirical Results}

In this section and the next, we study the gain between Euro-zone interest rates and output growth in 4 countries: namely in the Germany, France, the aggregated Euro-zone, and the UK. We focus on the Euro-zone comparison to represent the smaller Euro economies; and more importantly because that is the aggregate the common monetary is intended to manage. We include the UK as a natural outside comparator; an economy that chose not to join the common monetary policy but which is sufficiently close to be subject to many of the same shocks and external pressures. The UK can reasonably be taken to represent what might have happened to the Euro-zone economies had they not joined the Euro. It is important to have an external comparator such as this in order to be sure that any convergence effects that we pick up in the Euro-zone economies are genuine Euro-zone effects, and not a general phenomenon affecting all countries world-wide or Europe-wide. So the UK acts as the control group here

To make our estimates, we use quarterly, seasonally adjusted data for real GDP in all four economies, as published in the OECD Main Economic Indicators, and log difference them once to obtain growth rates. The resulting series were fitted to an ADL model as described above, and tested for stationarity, statistical significance and a battery of specification checks. The interest rates are 3 month T-bill rates for all countries. All the data are taken from the IMF's International Financial Statistics. 


\subsection{Germany}

The database for Germany starts in 1977Q1 and finishes in 2007Q2. Figure 1 shows the gain between the growth rate and the Euro interest rate.

- Figure 1 about here -

The gain went through very significant changes over time. Towards the end of the sample, the gain is characterised by two cycles: firstly, a cycle at a frequency of 2.5 , or 2.5 quarters; and a second one at a frequency of 1.1 or 1.72 quarters. However, these cycles only emerged permanently after the start of the monetary union in 1999; there was no anticipation of the effects of the change in the German economy. Before EMU, these same cycles had emerged temporarily at periods of particular stress in the ERM regime in 1984 and 1991. Indeed these periods of effective independence from the thrust of European monetary policies, German leadership in the hard-EMS regime (1985-1990), and in the aftermath of German reunification (1992-1999), are particularly clear. That said, it is interesting to note that European monetary policies do not lead to a large degree of uncertainty for the annual growth rate as the importance of the high frequencies (noise) is very low. This result is in contrast to the quarterly growth rate (see: Richter, 2007). Hence the choice of the annual or quarterly growth rate matters.

Importantly, the introduction of the Euro in 1999 has clearly changed the monetary transmission mechanism. The key question now is, is this change in line with the transmission mechanisms of France and the Euro-zone as a whole?

Last but not least, from table 1 we can see that the interest rate is able to explain about $98 \%$ of the variance of the growth rate. Indeed the diagnostics show a strong and stable relationship underlies these gain calculations. As the residuals are not autocorrelated, we can also describe our results as robust.

- Table 1 about here -

\subsection{France}

The French data sample starts in 1972Q1 and finishes in 2008Q1. Figure 2 shows the gain between the French growth rate and the Euro interest rate. 
- Figure 2 about here -

In contrast to the German gain, the French gain is almost always characterised by the same two cycles which emerged in Germany after the introduction of the Euro. This suggests that France was always the follower to European monetary policies in the way that Germany now is to the ECB. There was a short period during the breakdown of the EMS in 1990-1994 when the relationship between Euro interest rates and French growth collapsed and vanished; also during the imposition of the hard EMS peg in 1985-87. Otherwise the French gain, or dependence on European interest rates has remained constant, if weaker than in the early days of the EMS and not as strong as the German dependence now is.

Hence, the transmission mechanisms of Germany and France have converged in the sense that Germany has now accepted the same kind of transmission mechanism that France has always had. That is, Europe-wide interest rates now have the same type of effect in Germany as they do in France. However, the impact of any changes in Euro interest rates on Germany is now twice as strong as they are in France. In that sense Germany is now far more sensitive to, and more dependent on, changes in the direction or force of European monetary policy than France. This may have significant implications in terms of producing differences in economic performance in the two economies. Convergence is therefore not complete, and differences of opinion over the appropriate stance of policy are likely to remain.

Thus, in contrast to Germany, the policy gains in France did not change with the introduction of the Euro. They had been in operation at least since the mid 1990s, and in the hard EMS period. It is remarkable too that whenever there was a shock and the shape of the gain disappeared, it re-appeared quite rapidly - typically after two or three years in this analysis. That was not the case in Germany.

Finally from the time domain regressions (table 2) we can see that the interest rate explains about $99 \%$ of the variance of the growth rate, and there is no autocorrelation. The diagnostics again show our results to be stable, significant and robust.

- Table 2 about here -

\subsection{European Monetary Union}

In this section we analyse how the EMU as whole behaves in response to monetary shocks. The EMU data contains France and Germany, but also all the other EMU countries 
apart from Slovenia and Malta ${ }^{6}$. The calculations in this section are not designed to show how far convergence has gone in terms of the policy responses in individual economies; but to show whether the rest of the Eurozone, beyond France and Germany, reacts to policy changes in the same way as France and Germany do. For data, we used the aggregated, seasonally adjusted real GDP of all EMU members to obtain a Euro-area growth rate. However, the approach has to be slightly different for interest rates since there is no common 3-month Tbill rate for the Euro area. Hence, for interest rates, we use GDP weighted averages of the 3month T-bill rates in the Eurozone. This is obviously an artificial rate. But it has been developed and used by the OECD as a suitable measure of the common market rates of interest, and the data for it have been taken from the OECD's Economic Outlook. The time series starts in 1970Q1 and ends in 2008Q1. Given the results of the two previous sections, the question we want to ask in this section is whether EMU has followed the German model or the French model more closely for setting monetary policy, and how effective the current monetary transmission mechanism has been for the Euro economy as a whole.

Figure 3 shows the gains for EMU as a region in response to Euro interest rates. Perhaps unsurprisingly, the Euro-zone has followed the French model of monetary policy. The same two cycles (at frequencies of 1.1 and 2.5) dominate, although with a slightly stronger impact effect of 0.5 instead of 0.35 as in France. It is tempting to think that this might be the influence of the stronger impacts of monetary policy in Germany. But those higher impacts in Germany (at 0.6) appear only after 2001. So this is a genuine "rest of EMU" effect; indeed the impact in the rest of EMU must have been considerably stronger than in France until 2000 since the gains in Germany in that period were close to zero. But since then the transmission effects have remained broadly constant with the coming of EMU, despite the stronger German component, which means that there has been a good deal of convergence within the rest of the Eurozone and it is more towards the French transmission mechanism than the German one. So even in the years of the currency snake where France followed German monetary policy, the transmission mechanism elsewhere was characterised more by the French channel rather than the German channel. That seems to be surprising at first glance, but may actually be the reason why in the currency snake and the EMS exchange rates had to be adjusted several times. It also shows that during this period, the long term effects of monetary policy were different for at least two countries (if not a majority). So for many of the ERM countries, participation in the hard EMS may have been suboptimal for growth. That

\footnotetext{
${ }^{6}$ Malta and Slovenia were omitted in order to avoid another structural break.
} 
only changed with the introduction of the Euro, when Germany lost control and had to adjust to the rest of Europe.

- Figure 3 about here -

A look at the time domain results (table 3) reveals that the lag structure of the EMU is indeed closer (although not identical) to France than to Germany. However, the regression results also show that Euro-zone growth rates are determined by other factors beyond interest rates. In fact the Euro-zone rates explain only $40 \%$ of the growth rate. The other diagnostics imply a stable relationship. The explanation for no autocorrelation of the residuals is that the time variation of the intercept term serves as an unobserved component in this regression. So it catches systematic exogenous shocks to the system.

- Table 3 about here -

There is one qualification to add to this story. The gains in the transmission of monetary policies in the Euro-zone have started to fall away since 2005, while they have remained the same or strengthened in Germany (and France). If this is sustained beyond 2008, it will mean that the Euro-zone has started to diverge again in terms of monetary responses in this case divergence between core and periphery, rather than between each country pair.

\subsection{The UK}

Given the results gained so far, we now widen our scope and analyse a country outside EMU. The UK is an interesting case because it did not participate in the exchange rate mechanism, nor has it joined the Euro, but it clearly plays a very large role in the European financial markets. Indeed, London has become the most important financial centre in Europe. So how does the UK transmission mechanism behave? Is it, or has it become broadly similar to those in the rest of Euro-zone? We know from Richter (2007) that short term interest rate effects in the UK and France are similar. Does that also hold for Germany, and in annual growth rates too? Last, but most important, comparisons with the UK as outside comparator will show whether the degree of convergence that we have uncovered in this paper is a feature specific to Europe and her single currency, or whether it is a general phenomenon shared by other economies at a similar level of development (a globalisation phenomenon).

For the UK, the sample starts in 1966Q1 and finishes in 2008Q1. Figure 4 shows the gains between UK growth rates and short term interest rates.

- Figure 4 about here - 
The answer is that superficially the UK transmission mechanism looks to be similar to that in the Euro-zone and in France (the difference here is mainly in the greater stability in the UK, vs. the instability of the French transmissions in the collapse of the EMS in the early 90s and mid 1980s). The UK gains are also characterised by two cycles, at similar strength to the Euro-zone but stronger than in France (at least from the start of the EMS regime onwards). However these two cycles are at frequencies of 1.3 and 2.6. They increased in power in 1980, the start of the EMS, held constant till 1996; but then declined in power steadily, but not fast, at least until the end of 2007. At that point they still dominated, but at a strength similar to the Euro-zone and France (but less than Germany). And the decline, though longer and slower than that in the Euro-zone as a whole, probably parallels the divergence we have noted in the periphery economies of the Euro-zone. Hence the transmission mechanism in the UK seems to be close to that of EMU as a whole, but not to Germany or perhaps France. It is therefore no surprise that the UK, as the dominant financial market place, left ERM in 1992. If the arrangement was already suboptimal for most EMU countries, it clearly was suboptimal for the UK, so much so that the UK was better off leaving the system.

However, this situation may not continue to hold. To the extent that the UK remains in line with EMU as a whole, and given that Germany has now converged to EMU, participation in the Euro by the UK might now be easier than it was before. Yet the UK does not share in the sudden weakening of transmissions in the Euro-zone after 2005; nor in their strengthening in Germany, nor the instability in France. So if the UK has been part of a divergence club in the past few years, it has not seen the same divergence as elsewhere. Indeed, looking at the UK's lag structure in table 4, one can see that it is different to the lag structure in the Eurozone. The reason why a different lag structure has led to similar outcomes (until 2005) is that the additional UK lags are much smaller in weight, about one half, than the lags which are important for EMU. That is happenstance, and may change in this time-varying world. And if it does change then the monetary transmission channels for the UK may become completely different again to those in the Euro-zone.

- Table 4 about here -

To summarise, there has been something of a globalisation effect in the convergence of the monetary transmissions in Europe. The UK may have had rather different monetary transmissions in the instability period of the early 1990s, and was perhaps well advised to leave the ERM at that point. But she had a period of similar transmissions to the Euro-zone until 2005, and to a lesser extent France (but not Germany). After 2005, she may have 
participated in the general divergence in the periphery economies from the core. Yet there are now signs that her participation in even that divergence is temporary and could easily fade.

\section{Conclusion}

This paper has made three contributions. First we have presented a technique by which the transmission mechanism can be decomposed into its component cycles and compared across economies; and we have shown how that can be done such that the transmission mechanisms, and the relative importance of their cycles, can vary over time. As a result, we found that the individual data generating processes have varied over time.

Second we have shown how to apply these methods to answer the question: are transmission mechanisms different and if so, are they converging? The interesting result is here that Germany has now converged on the rest of Europe and not vice versa, although Germany had dominated monetary policy making in Europe for many years. The good news is that this should have a stabilising effect on the European monetary policy. The bad news is that the other countries stayed for political reasons in an exchange rate mechanism which was suboptimal for them. The reasons that made it suboptimal for them are now reappearing without the same compelling political reasons to keep focussed on convergence. The single currency will keep them in, but that does not keep their political responses in line.

The UK as an outsider has behaved like a peripheral EMU country, even when EMU was not in place. But when that German monetary policy dominated Europe in a way that was not in line with the rest of Europe, never mind the UK, it is no surprise that the UK eventually left the ERM. However, things have changed since then and for a time monetary policy has had similar long term effects in UK and in the rest of Europe. The current financial crisis may enforce this trend. But there have been signs of a divergence between core and periphery, to some extent involving the UK, so this general convergence, as opposed to tighter convergence in the core, may not last.

\section{References}

Barran, F., Coudert, V., and Mojon, B. (1995): The Transmission of Monetary-Policy and Bank - The Case of 3 OECD Countries. Revue Economique 46, 393-413.

BIS (1995): Financial Structure and the Monetary Policy Transition Mechanism. Bank for International Settlements, Basel, Switzerland CB394. 
Boashash, B. (2003): Time Frequency Signal Analysis and Processing, Elsevier, Oxford.

Boashash, B., and Reilly, A. (1992): Algorithms for time-frequency signal analysis, pp. 163181. In B. Boashash (Ed.): Time-Frequency Signal Analysis - Methods and Applications, Longman-Cheshire, Melbourne.

Boivin, J., and Giannoni, M. P. (2006): Has monetary policy become more effective? Review of Economics and Statistics 88, 445-462.

Campbell, J. Y., and Mankiw, N. G. (1987): Permanent and Transitory Components in Macroeconomic Fluctuations. American Economic Review 77, 111-117.

Carlino, G. and De Fina, R. (1999): Monetary Policy in the US States and Regions: some implications for the European Monetary Union, in J. von Hagen and C. Waller (eds): Regional Aspects of Monetary Policy in Europe, Kluwer Academic Publishers, Boston and Dordrecht.

Cecchetti, S. (1999): Legal Structure, Financial Structure and the Monetary Transmission Mechanism, Economic Policy Review, Federal Reserve of New York, New York, July.

Chauvet, M., and Potter, S. (2001): Recent Changes in the US Business Cycle. Manchester School 69, 481-508.

Clark, P. K. (1987): The Cyclical Component of the U.S. Economic Activity. Quarterly Journal of Economics 102, 797-814.

Dale, S., and Haldane, G. (1995): Interest Rates and Channels of Monetary Transmission: some sectoral estimates. European Economic Review 39, 1611-1626.

Dedola, L., and Lippi, F. (2005): The monetary transmission mechanism: evidence from the industries of five OECD countries. European Economic Review; Amsterdam 49, 1543.

Fukuda, S. (1993): International Transmission of Monetary and Fiscal-Policy - A Symmetrical N-Country Analysis with Union. Journal of Economic Dynamics and Control 17, 589-620.

Gabor, D. (1946): Theory of communication. Journal of the Institute of Electrical Engineering 93, 429 - 457.

Golinelli, R., and Rovelli, R. (2005): Monetary policy transmission, interest rate rules and inflation targeting in three transition countries. Journal of Banking and Finance 29, 183-201.

Goodhart, C., and Hofmann, B. (2005): The IS curve and the transmission of monetary policy: is there a puzzle? Applied Economics 37, 29-36.

Hughes Hallett, A., and Piscitelli, L. (1999): EMU in Reality: The Effect of a Common Monetary Policy on Economies with Different Transition Mechanisms Empirica 26 337-358.

Hughes Hallett, A., and Piscitelli, L. (2002): Does One Size Fit All? A Currency Union with Asymmetric Transmissions and a Stability Pact. International Review of Applied Economics 16, 71 - 96.

Hughes Hallett, A., and Richter, C. (2002): Are Capital Markets Efficient? Evidence from the Term Structure of Interest Rates in Europe. Economic and Social Review 33, 333 356. 
Hughes Hallett, A., and Richter, C. (2003a): Learning and Monetary Policy in a Spectral Analysis Representation, pp. 91-103. In P. Wang, and S.-H. Chen (Eds): Computational Intelligence in Economics and Finance, Springer Verlag, Berlin.

Hughes Hallett, A., and Richter, C. (2003b): A Spectral Analysis of the Short-End of the British Term Structure, pp. 123-128. In R. Neck (Ed.): Modelling and Control of Economic Systems, Elsevier, Amsterdam.

Hughes Hallett, A., and Richter, C. (2004): Spectral Analysis as a Tool for Financial Policy: An Analysis of the Short End of the British Term Structure. Computational Economics 23, 271-288.

Hughes Hallett, A., and Richter, C. (2006a): Is the Convergence of Business Cycles a Global or Regional Issue? The UK, US and Euroland. Journal of International Finance and Economics 11, 177-194.

Hughes Hallett, A., and Richter, C. (2006b): Measuring the Degree of Convergence among European Business Cycles. Computational Economics 27, 229-259.

Ireland, P., and Boston, C. (2005): The Monetary Transmission Mechanism. Boston College Working Papers in Economics: 628, 1-14.

Kashyup, A. and Stein, J. (1997): The Role of Banks in Monetary Policy: a survey with implications for EMU, Economic Perspectives, Federal Reserve of Chicago, Chicago, XXI, 2-18.

Kim, S. U. I., and Korea, U. (2003): Monetary Policy Rules and Business Cycles. Scandinavian Journal of Economics 105, 221.

LaMotte, L. R., and McWorther, A. J. (1978): An exact test for the presence of random walk coefficients in a linear regression. Journal of the American Statistical Association 73, 816-820.

Lin, Z. (1997): An Introduction to Time-Frequency Signal Analysis. Sensor Review 17, 4653.

Lovrinovic, I., Zagreb, U., and Benazic, M. (2004): A VAR Analysis of Monetary Transmission Mechanism in the European Union. Zagreb International Review of Economics and Business 7, 27.

Lutkepohl, H., and Wolters, J. (2003): Transmission of German monetary policy in the preEuro period. Macroeconomic Dynamics 7, 711-733.

MacLennan, D., Muellbauer, J., and Stephens, M. (2000): Asymmetries in Housing and Financial Market Institutions and EMU In T. Jenkinson (Ed.): Readings in Macroeconomics Oxford University Press, Oxford.

Matz, G., and Hlawatsch (2003): Time-Varying Power Spectra of Nonstationary Random Processes. In B. Boashash (Ed.): Time Frequency Signal Analysis and Processing, Elsevier, Amsterdam.

Peersman, G., and Ghent, U. (2004): The Transmission of Monetary Policy in the Euro Area: Are the Effects Different across Countries? Oxford Bulletin of Economics and Statistics 66, 285.

Ploberger, W., Krämer, W., and Kontrus, K. (1989): A New Test For Structural Stability in the Linear Regression Model. Journal of Econometrics 40, 307-318.

Ramaswamy, R., and Sloek, T. (1998): The Real Effects of Monetary Policy in the European Union: what are the differences? IMF Staff Papers 45. 
Richter, C. (2007): On the Transmission Mechanism of Monetary Policy, pp. $241-257$. In R. Neck, C. Richter, and P. Mooslechner (Eds): Quantitative Economic Policy, Springer, Heidelberg.

Schmidt, C. (2006): International transmission effects of monetary policy shocks: Can asymmetric price setting explain the stylized facts? International Journal of Finance and Economics 11, 205-218.

Todd, J. (2003): Stationarity of Health Expenditures and GDP; Evidence from Panel Unit Root Tests with heterogeneous Structural Breaks. Journal of Health Economics 22, 313-323.

Watson, M. W. (1986): Univariate Detrending Methods with Stochastic Trends. Journal of Monetary Economics 18, 49-75.

Wells, C. (1996): The Kalman Filter in Finance. Kluwer Academic Publishers. Dordrecht.

\section{Appendix 1: Short Time Fourier Transform}

Consider a signal $\mathrm{s}(\tau)$ and a real, even window $w(\tau)$, whose Fourier transforms are $\mathrm{S}(\mathrm{f})$ and $\mathrm{W}(\mathrm{f})$ respectively. To obtain a localised spectrum $\mathrm{s}(\tau)$ at time $\tau=\mathrm{t}$, we multiply the signal by the window $w(\tau)$ centred at time $\tau=\mathrm{t}$. We obtain

$$
\mathrm{S}_{w}(\mathrm{t}, \tau)=\mathrm{s}(\tau) w(\tau-\mathrm{t})
$$

We then calculate the Fourier transform w.r.t. $\tau$ which yields

$$
\mathrm{F}_{\mathrm{s}}^{w}(\mathrm{t}, \mathrm{f})=\underset{\tau \rightarrow \mathrm{f}}{F}\{\mathrm{~s}(\tau) w(\tau-\mathrm{t})\}
$$

$F_{s}^{w}(t, f)$ is the STFT. It transforms the signal into the frequency domain across time. It is therefore a function of both. Using a bilinear kernel and a Gabor transform (the time series is stationary, but may contain parameter changes), Boashash and Reilly (1992) show that the STFT can always be expressed as a time-varying discrete fast-Fourier transform calculated for each point in time. That has the convenient property that the "traditional" formulae for the coherence or the gain are still valid, but have to be recalculated at each point in time. The time -varying spectrum of the growth rate series can therefore be calculated as (see also: Lin, 1997):

$$
P_{t}(\omega)=\frac{\sigma^{2}}{\left|1+\sum_{i=1}^{9} \alpha_{i, t} \exp (-j \omega i)\right|_{t}^{2}}
$$


where $\omega$ is angular frequency and $\mathrm{j}$ is a complex number and $\alpha$ are the estimated coefficients. The main advantage of this method is that, at any point in time, a power spectrum can be calculated instantaneously from the updated parameters of the model (see also Lin, 1997). Similarly, the power spectrum for any particular time interval can be calculated by averaging the filter parameters over that interval.

\section{Appendix 2: Statistical Results}

Note: For reasons of space, the results quoted in the tables describe the final regression done and its diagnostic tests. But the figures which follow display the period by period spectral results.

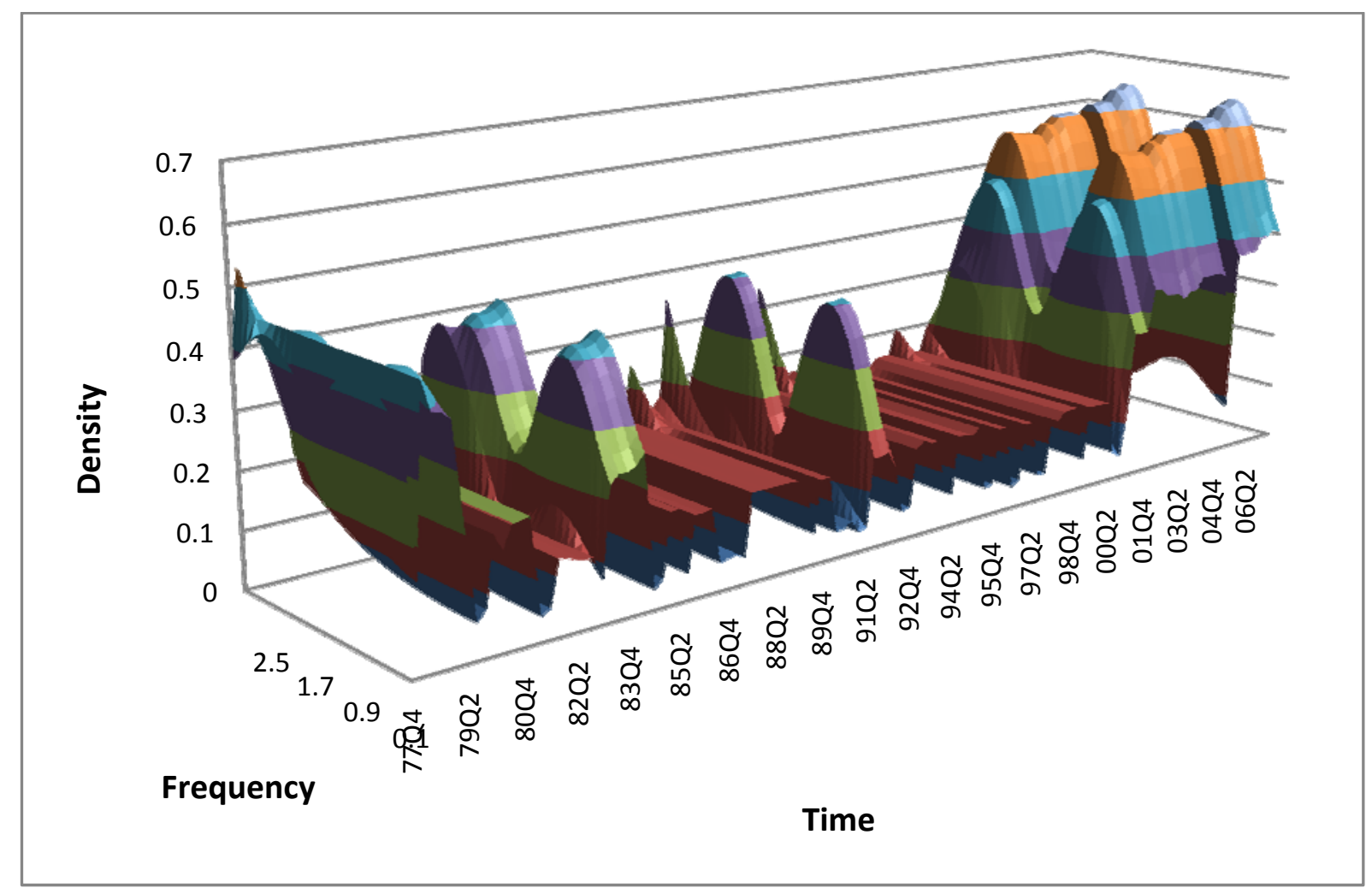

Figure 1: Gain between Euro Interest Rates and German GDP 


\begin{tabular}{||l|l|l|l||}
\hline \multicolumn{4}{|c|}{ VAR/System - Estimation by Kalman Filter } \\
\hline Dependent Variable & DLGERGDP & Quarterly Data From & $\begin{array}{l}1977: 01 \text { To } \\
2007: 02\end{array}$ \\
\hline Usable Observations & 122 & $\begin{array}{l}\text { Std Error of } \\
\text { Dependent Variable }\end{array}$ & 7.344034908 \\
\hline $\mathrm{R}^{2}$ & 0.98837 & $\begin{array}{l}\text { Standard Error of } \\
\text { Estimate }\end{array}$ & 4.953864717 \\
\hline $\begin{array}{l}\text { Mean of Dependent } \\
\text { Variable }\end{array}$ & -0.037649496 & $\begin{array}{l}\text { Sum of Squared } \\
\text { Residuals }\end{array}$ & 2871.2707493 \\
\hline Akaike (AIC) Criterion & 0.68802 & $\begin{array}{l}\text { Ljung-Box Test: } \\
\text { Q*(21) }\end{array}$ & 33.0404 \\
\hline Variable & Coeff & Std Error & T-Stat \\
\hline Constant & 0.92915083 & 0.069017425053 & 13.46255430988 \\
\hline DLGERGDP $\{1\}$ & -0.83350102 & 0.862330010393 & -0.966568496268 \\
\hline GERINT & -0.51877805 & 0.180640176422 & -2.87188631575 \\
\hline GERINT $\{1\}$ & 0.12575100 & 0.037446995505 & 3.358106480903 \\
\hline
\end{tabular}

Table 1: Regression Results: German Growth Rate and Euro Interest Rates

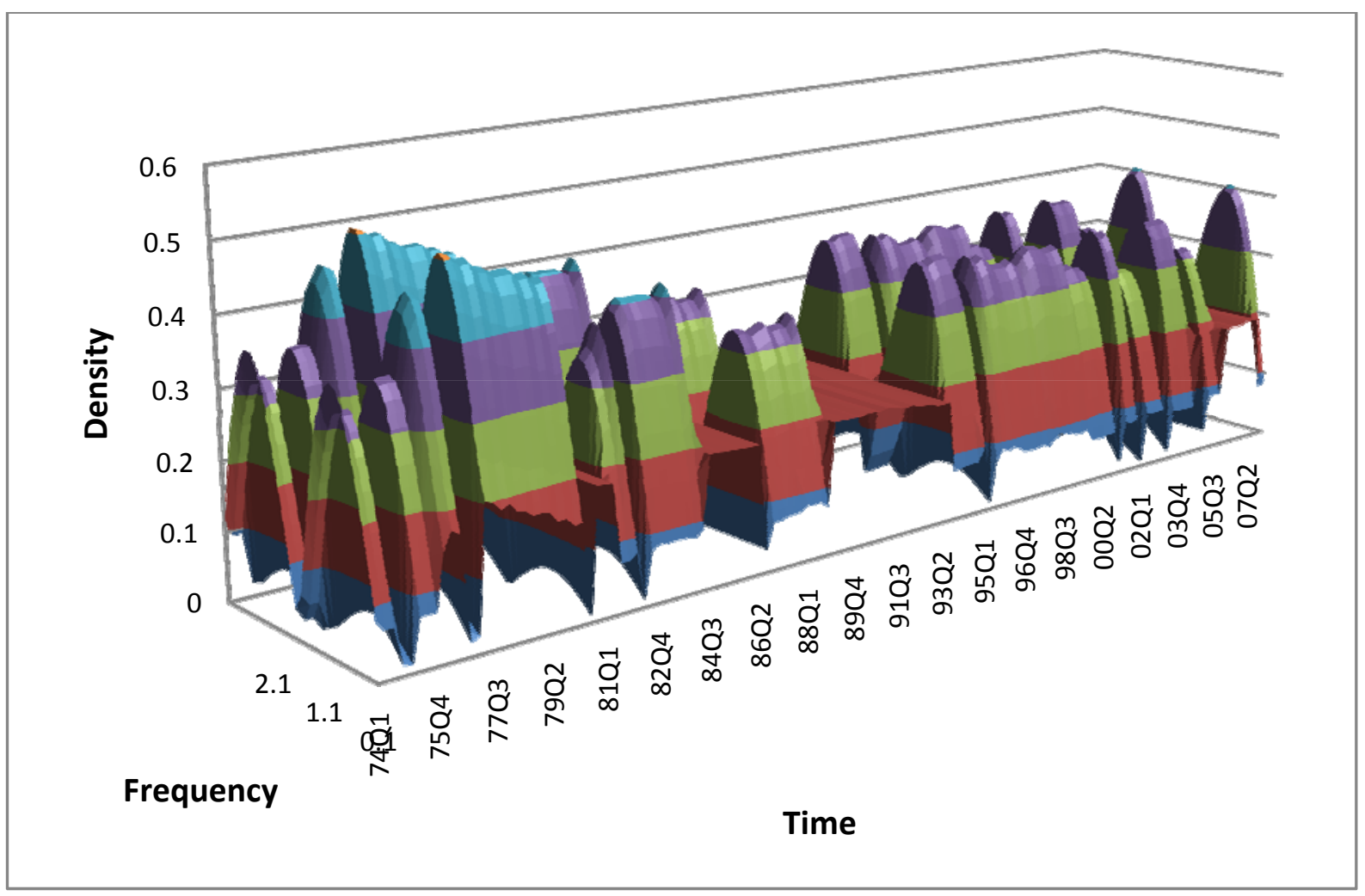

Figure 2: Gain between Euro Interest Rates and the French Growth Rate 


\begin{tabular}{||l|l|l|l||}
\hline \multicolumn{4}{|c|}{ VAR/System - Estimation by Kalman Filter } \\
\hline Dependent Variable & DLFRGDP & Quarterly Data From & $\begin{array}{l}1972: 01 \text { To } \\
2008: 01\end{array}$ \\
\hline Usable Observations & 144 & $\begin{array}{l}\text { Std Error of } \\
\text { Dependent Variable }\end{array}$ & 1.8633178724 \\
\hline $\mathrm{R}^{2}$ & 0.99882 & $\begin{array}{l}\text { Standard Error of } \\
\text { Estimate }\end{array}$ & 5.7263454851 \\
\hline $\begin{array}{l}\text { Mean of Dependent } \\
\text { Variable }\end{array}$ & 0.0083842572 & $\begin{array}{l}\text { Sum of Squared } \\
\text { Residuals }\end{array}$ & 4623.5355987 \\
\hline Akaike (AIC) Criterion & 0.70189 & $\begin{array}{l}\text { Ljung-Box Test: } \\
\text { Q*(26) }\end{array}$ & 35.7327 \\
\hline Variable & Coeff & Std Error & T-Stat \\
\hline Constant & 0.14457851 & 0.030366950564 & 4.7610481630 \\
\hline DLFRGDP $\{2\}$ & 3.03444661 & 2.248747036208 & 1.349394378080 \\
\hline FRINT & 0.18960241 & 0.012935754672 & 14.65723611884 \\
\hline FRINT $\{1\}$ & -0.217076786 & 0.072575370699 & -2.99105302958 \\
\hline
\end{tabular}

Table 2: Regression Results: the French Growth Rate and Euro Interest Rates

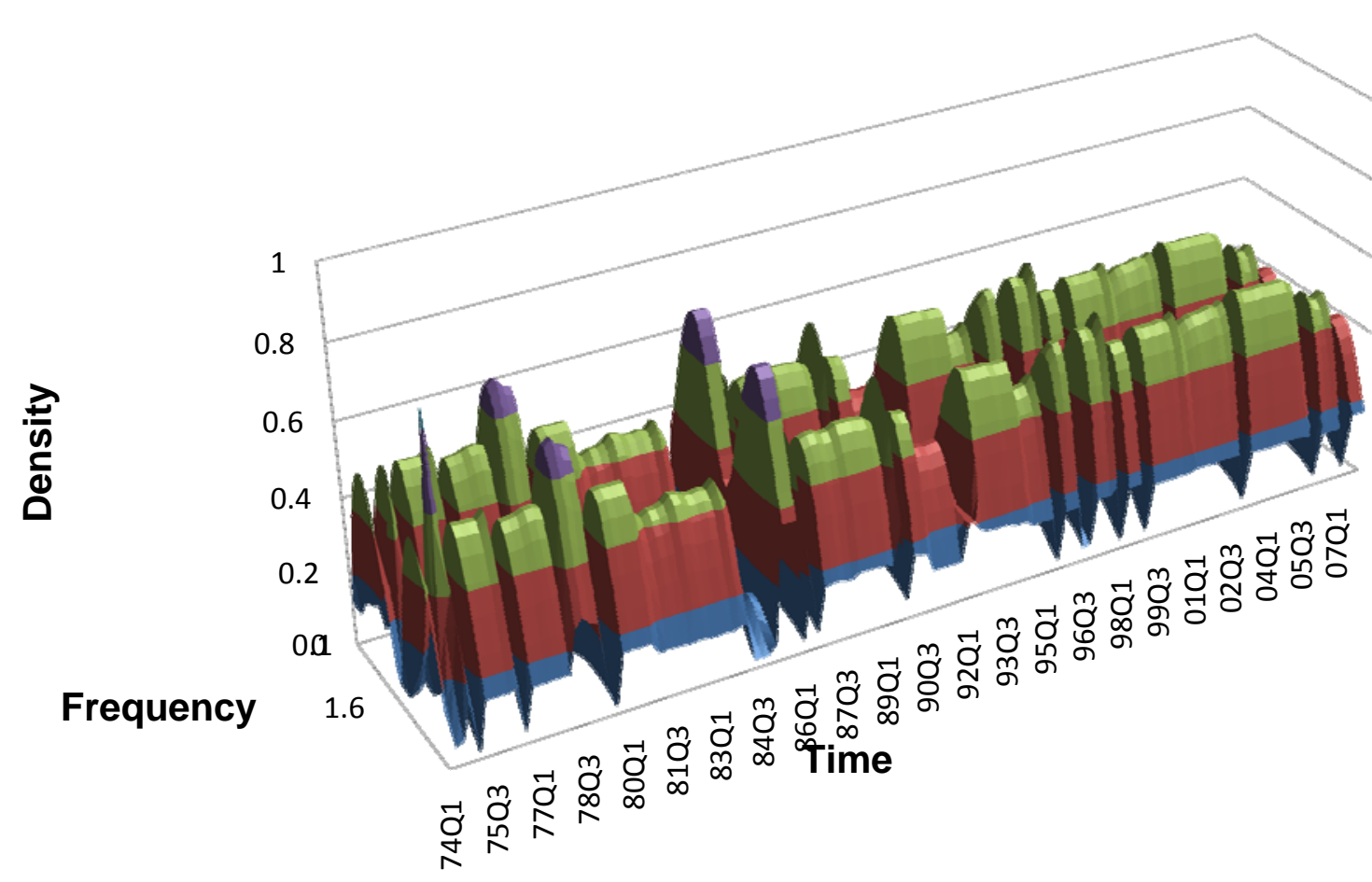

Figure 3: Gain between EMU Growth Rate and Euro Interest Rates 


\begin{tabular}{||l|l|l|l||}
\hline \multicolumn{4}{|c|}{ VAR/System - Estimation by Kalman Filter } \\
\hline Dependent Variable & DLEMUGDP & Quarterly Data From & $\begin{array}{l}1970: 01 \text { To } \\
2008: 01\end{array}$ \\
\hline Usable Observations & 145 & $\begin{array}{l}\text { Std Error of } \\
\text { Dependent Variable }\end{array}$ & 1.8916279266 \\
\hline $\mathrm{R}^{2}$ & 0.40258 & $\begin{array}{l}\text { Standard Error of } \\
\text { Estimate }\end{array}$ & 2.6225880721 \\
\hline $\begin{array}{l}\text { Mean of Dependent } \\
\text { Variable }\end{array}$ & 0.0023331688 & $\begin{array}{l}\text { Sum of Squared } \\
\text { Residuals }\end{array}$ & 962.91554742 \\
\hline Akaike (AIC) Criterion & 0.01512 & $\begin{array}{l}\text { Ljung-Box Test: } \\
\text { Q*(24) }\end{array}$ & 22.6655 \\
\hline Variable & Coeff & Std Error & T-Stat \\
\hline Constant & -0.09454859 & 0.038465000620 & -2.45804203950 \\
\hline DLEMUGDP $\{3\}$ & -0.76789776 & 2.549985465622 & -0.301138094484 \\
\hline EMUINT & 0.12742306 & 0.076250929192 & 1.671101732675 \\
\hline EMUINT $\{1\}$ & -0.26594720 & 0.035038487742 & -7.59014483447 \\
\hline
\end{tabular}

Table 3: Regression Results: the EMU Growth Rate and Euro Interest Rates

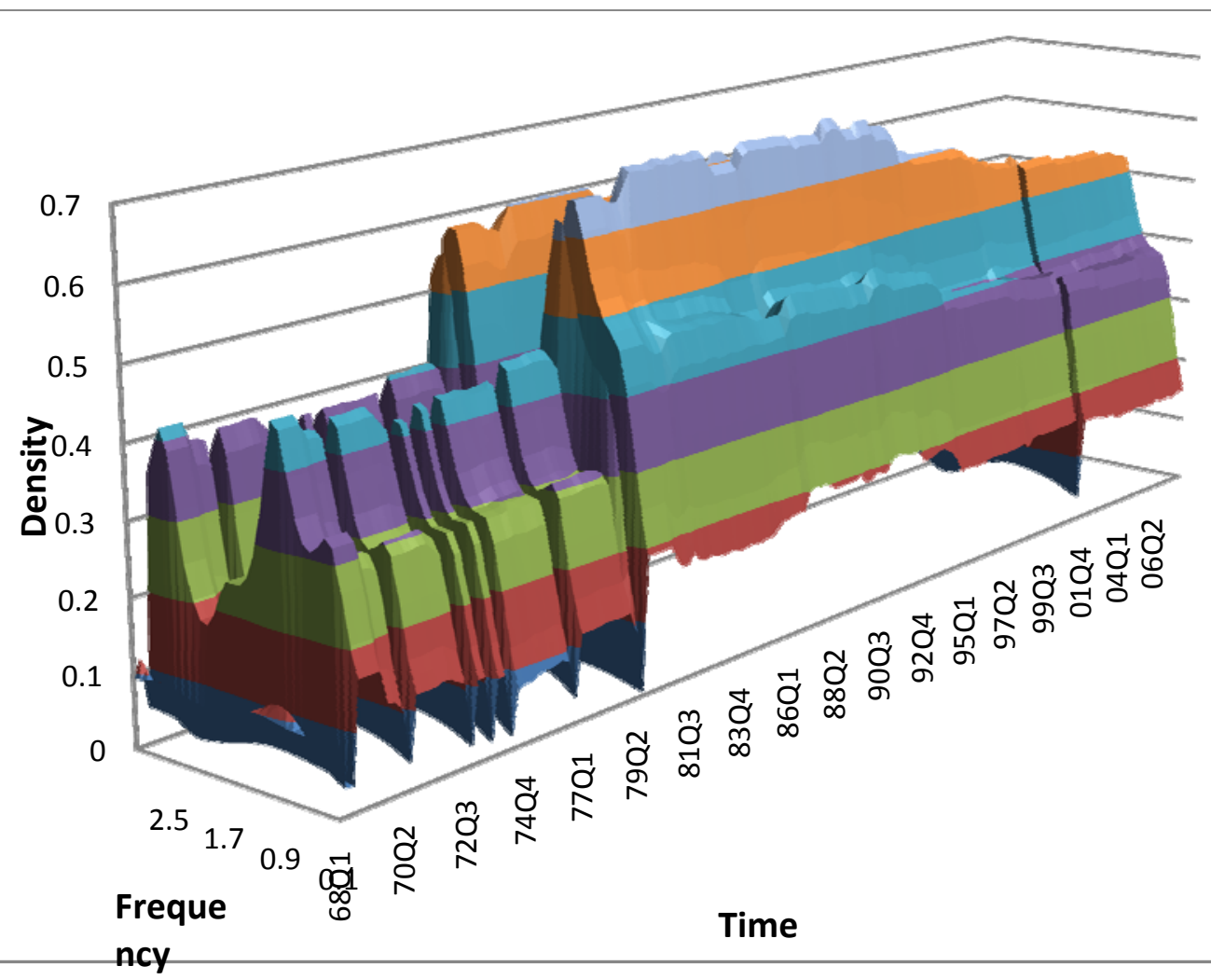

Figure 4: Gain between the UK Growth Rate and Euro Interest Rates 


\begin{tabular}{||l|l|l|l||}
\hline \multicolumn{5}{|c|}{ VAR/System - Estimation by Kalman Filter } \\
\hline Dependent Variable & DLUKGDP & Quarterly Data From & $\begin{array}{l}1966: 01 \text { To } \\
2008: 01\end{array}$ \\
\hline Usable Observations & 169 & $\begin{array}{l}\text { Std Error of } \\
\text { Dependent Variable }\end{array}$ & 4.3055685240 \\
\hline $\mathrm{R}^{2}$ & 0.98995 & $\begin{array}{l}\text { Standard Error of } \\
\text { Estimate }\end{array}$ & 4.9772938011 \\
\hline $\begin{array}{l}\text { Mean of Dependent } \\
\text { Variable }\end{array}$ & 0.0023204919 & $\begin{array}{l}\text { Sum of Squared } \\
\text { Residuals }\end{array}$ & 4038.0729340 \\
\hline Akaike (AIC) Criterion & 0.20073 & $\begin{array}{l}\text { Ljung-Box Test: } \\
\text { Q*(26) }\end{array}$ & 20.2142 \\
\hline Variable & Coeff & Std Error & T-Stat \\
\hline Constant & 0.685210687 & 1.171592652093 & 0.584854032314 \\
\hline DLUKGDP $\{2\}$ & 0.817373815 & 2.650584706442 & 0.308374907941 \\
\hline DLUKGDP $\{8\}$ & -0.120035372 & 0.023446142261 & -5.11962142703 \\
\hline UKINT $\{2\}$ & 0.163644836 & 0.033876378444 & 4.830647294398 \\
\hline UKINT $\{5\}$ & -0.310839329 & 0.055562194434 & -5.59443938632 \\
\hline
\end{tabular}

Table 4: Regression Results: the UK Growth Rate and Euro Interest Rates 